\title{
Connection Performance Examination of a New Bamboo- Oriented Strand Board Connector
}

\author{
Runmin Xu, ${ }^{\text {a,1 }}$ Kaiting Zhang, ${ }^{\text {, } 1}$ Linyan Ren, ${ }^{\text {a,1 }}$ Fuli Wang, ${ }^{\text {a,1 }}$ Zhenzhen Zhu, ${ }^{a}$ Tingting Zhang, \\ Shengquan Liu, ${ }^{\mathrm{a}}$ Yelong Fang, ${ }^{\mathrm{b}}$ Yong Guo, ${ }^{\mathrm{a}, *}$ and Yuxia Chen ${ }^{\mathrm{a}, *}$
}

\begin{abstract}
Bamboo-oriented strand board (BOSB) with superior physical properties can be used in the furniture industry to alleviate wood shortages. Two types of plug-in connectors were designed in this paper: a splint-type connector and V-type connector. By cantilever bending, corner tension, and compression tests of L-type corner joints of BOSB and wood-oriented strand board (WOSB), the connection performance of the new connectors and six typical connectors was compared. The new connectors function like clamps, do not require that a screw or bolt pass into or through the board, and can be assembled repeatedly. The V-type connectors were more suitable for BOSB, and the joints exhibited the highest ultimate bending moment values $(133.9 \mathrm{~N} \cdot \mathrm{m}, 86.8 \mathrm{~N} \cdot \mathrm{m}, 117.7 \mathrm{~N} \cdot \mathrm{m})$. The splint connectors were more suitable for WOSB and their ultimate bending moment values $(57.1 \mathrm{~N} \cdot \mathrm{m}$, $45.3 \mathrm{~N} \cdot \mathrm{m}, 61.3 \mathrm{~N} \cdot \mathrm{m})$ were greater than the joints fixed by V-type connectors $(50.4$ $\mathrm{N} \cdot \mathrm{m}, 35.4 \mathrm{~N} \cdot \mathrm{m}, 46.1 \mathrm{~N} \cdot \mathrm{m})$. The results revealed that the connector performance affects the joint strength and that different plates were suitable for different connectors. A joint failure analysis revealed two simple failure modes for the two new connectors.
\end{abstract}

Keywords: Bamboo-oriented strand board; Plug-in connector; Removable connector

Contact information: a: College of Forest and Garden, Anhui Agricultural University, Hefei, 230036, China; $b$ : Anhui Longhua Bamboo Industry Co., Ltd, Lu'an, 237000, China;

*Corresponding authors: fly828828@163.com (Yong Guo) and sheherose@163.com (Yuxia Chen)

1: Runmin Xu, Kaiting Zhang, Linyan Ren, and Fuli Wang contributed equally to the work

\section{INTRODUCTION}

Although China has a large wooden furniture industry, the lack of timber resources mainly limits wooden furniture development ( $\mathrm{Fu}$ et al. 2017). Bamboo is the second largest forest resource. The species, area, and stock volume of bamboo forests in China are among the top in the world. Hence, China is recognized as the "bamboo kingdom". The short growth cycle of bamboo can alleviate the wood shortage problem (Biswas et al. 2011; Akinlabi et al. 2017; Bahari et al. 2017; Fu et al. 2017). Bamboo materials currently used for furniture production include round bamboo, bamboo-laminated timber, reconstituted bamboo lumber (Li 2001), bamboo plywood, etc. (Chaowana 2013), which are mainly processed from large-diameter moso bamboo. The bamboo utilization rate is less than $50 \%$ which means that there is a large resource waste. The process flow of bamboo-oriented strand board (BOSB) is similar to wood-oriented strand board (WOSB). It can be produced by subjecting bamboo waste to crushing, screening, drying, sizing, paving, and hot pressing (Sumardi and Suzuki 2013). Therefore, BOSB production can effectively improve the bamboo utilization rate. Meanwhile, BOSB density is 600 to $900 \mathrm{~kg} / \mathrm{m}^{3}$ (Yong et al. 2018), which is 1.5 to 2 times that of WOSB (Chen et al. 2010). In addition, its elastic modulus, tensile strength, and hardness are notably greater than those of WOSB (Apriani 2012; Febrianto et al. 2012; Febrianto et al. 2015). Bamboo-oriented strand board is a reputable material for furniture because of its dimensional stability (Wan-Si and Huang 2007; Zhang and Du 2007). However, in

Xu et al. (2021). "Clamp connectors for bamboo OSB," BioResources 16(2), 2906-2920. 2906 
contrast to WOSB, BOSB is a harder material, leading to facile tool breakage which makes it difficult to perform machining. Can a plug-in connector be specifically developed for a BOSB connection? The plug-in connection can reduce the plate processing steps, thereby reducing the processing difficulty and costs.

The structural strength of furniture considerably depends on the connector type, the connector material, and the connection form (Qiang 2008; Ratnasingam and Ioras 2013). Sadegh et al. (2012) have examined the effect of spline material and connection form on the strength of a medium-density fiberboard joint and report that different materials need different connection forms. Guo et al. (2019) have reported that the moment resistance capacity of BOSB members connected by a converse-spine nut joint is greater than the two-in-one and three-in-one connectors, while the moment resistance capacity of particleboard members connected by a converse-spine nut joint is less than the two-in-one and three-in-one connectors. This further demonstrates that connector types affect the strength of members and that different materials need to match different connectors. In addition, Dalvand et al. (2013) and Vassiliou and Barboutis (2005) have independently reported that the connector material and connection form affect the strength, force condition, and failure mode of the members. The plate is inserted into the connector by the plugin structure (Seitz et al. 2003), which is fixed by friction between the connector and plate. Therefore, if the connector material and connection form cannot match the plate, it may cause damage to the plate surface and reduce the strength of the members.

Therefore, two new plug-in connectors were designed in this work: a splint-type connector and a V-type connector. Through a comparison between WOSB and six typical connectors, the strength and failure mode of the members were analyzed, which provided a research basis for the application of BOSB in the furniture industry.

\section{EXPERIMENTAL}

\section{Materials}

Two new connectors

The two new connectors used friction to fix the panel, and the bonding force between the connector and panel could be increased by the pressure applied on the panel surface (using bolts to tighten). Traditional connectors of furniture joints, such as two-in-one, three-in-one, and corner code, all need to drill holes, with embedded nuts or set screws inserted into the plate. Obviously, this complex process will reduce production efficiency and increase production costs. Not only that, these processing steps will also cause damage to the board, thus affecting the strength of the connection. The two new connectors used friction to fix the panel, and the bonding force between the connector and panel could be increased by the pressure applied on the panel surface (using bolts to tighten). Thus, through the application of two new connectors, there was no need to punch or screw, and the panel was not damaged. In addition, multiple disassembly and assembly processes could happen. Concurrently, the number of disassembly and assembly processes slightly affects the connection performance. The molds were made by $3 \mathrm{D}$ printing technology, and then new connectors were obtained by casting aluminum alloy with the molds.

Figure 1 shows the V-type connector dimensions. The V-type connector was mainly composed of a fixed screw and two V-type splints. To use the connector, the screw length was first adjusted according to the panel thickness, the panels were then placed between the two V-type splints, and the screw was finally tightened using the two V-type splints to clamp the panel. 

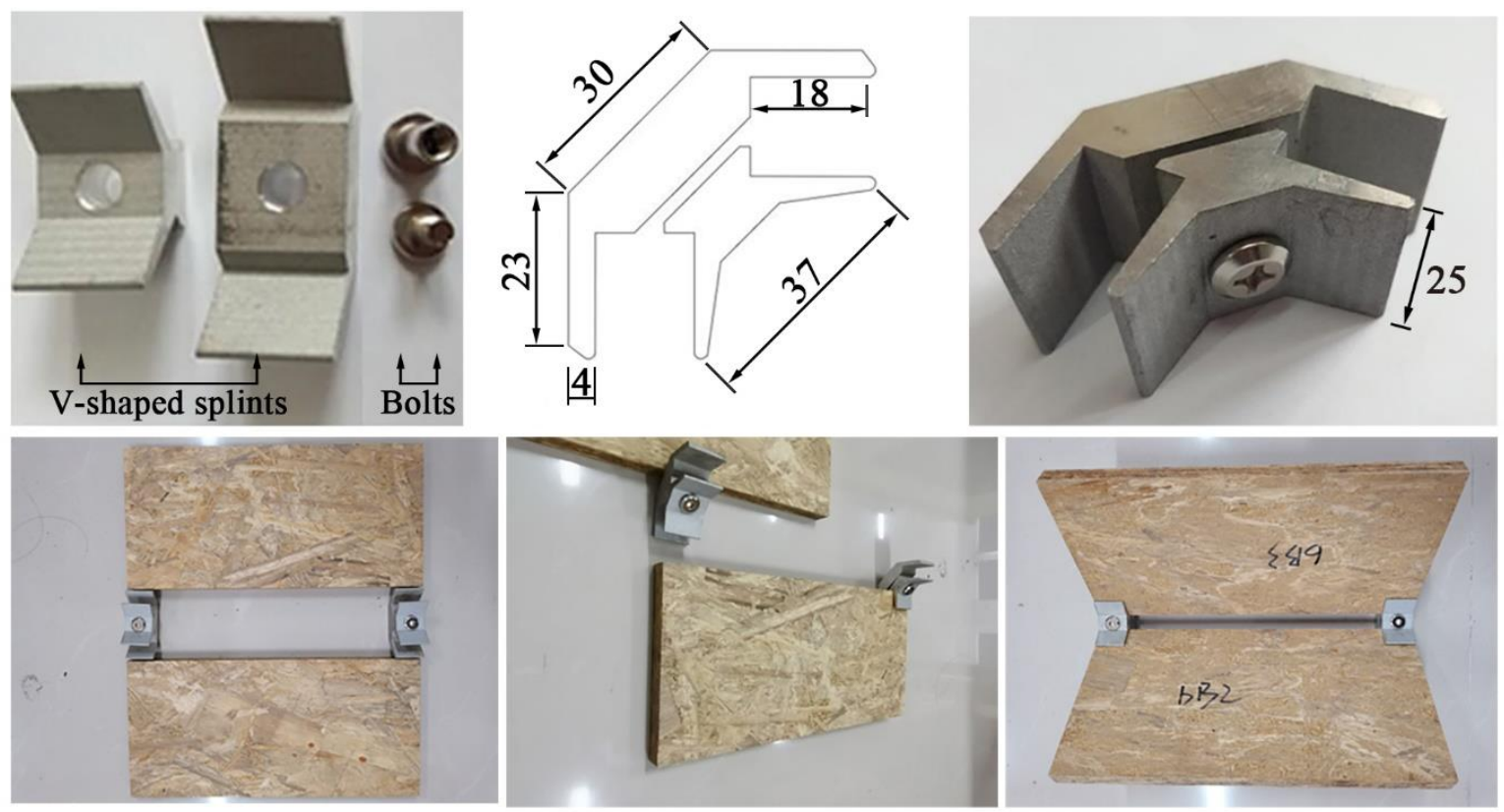

Fig. 1. V-type connector dimensions ( $\mathrm{mm}$ ) and installation modes

Figure 2 shows the splint-type connector. With an angle adjustment function, the connector mainly was composed of bolts, a central shaft, and splints. The bolts passed through the holes in the central shaft and head of the splints. The bolts were connected with a nut on the other side of the hole with a hexagon wrench to complete the splint pair assembly. Then, the same method was employed to assemble another pair of pliers. Notably, there was no need to completely tighten the bolts, thereby facilitating panel insertion. Finally, when the panel was inserted into the gap between the splint, the bolt was further tightened again with a hexagon wrench until the panel and splinttype connector were completely assembled.
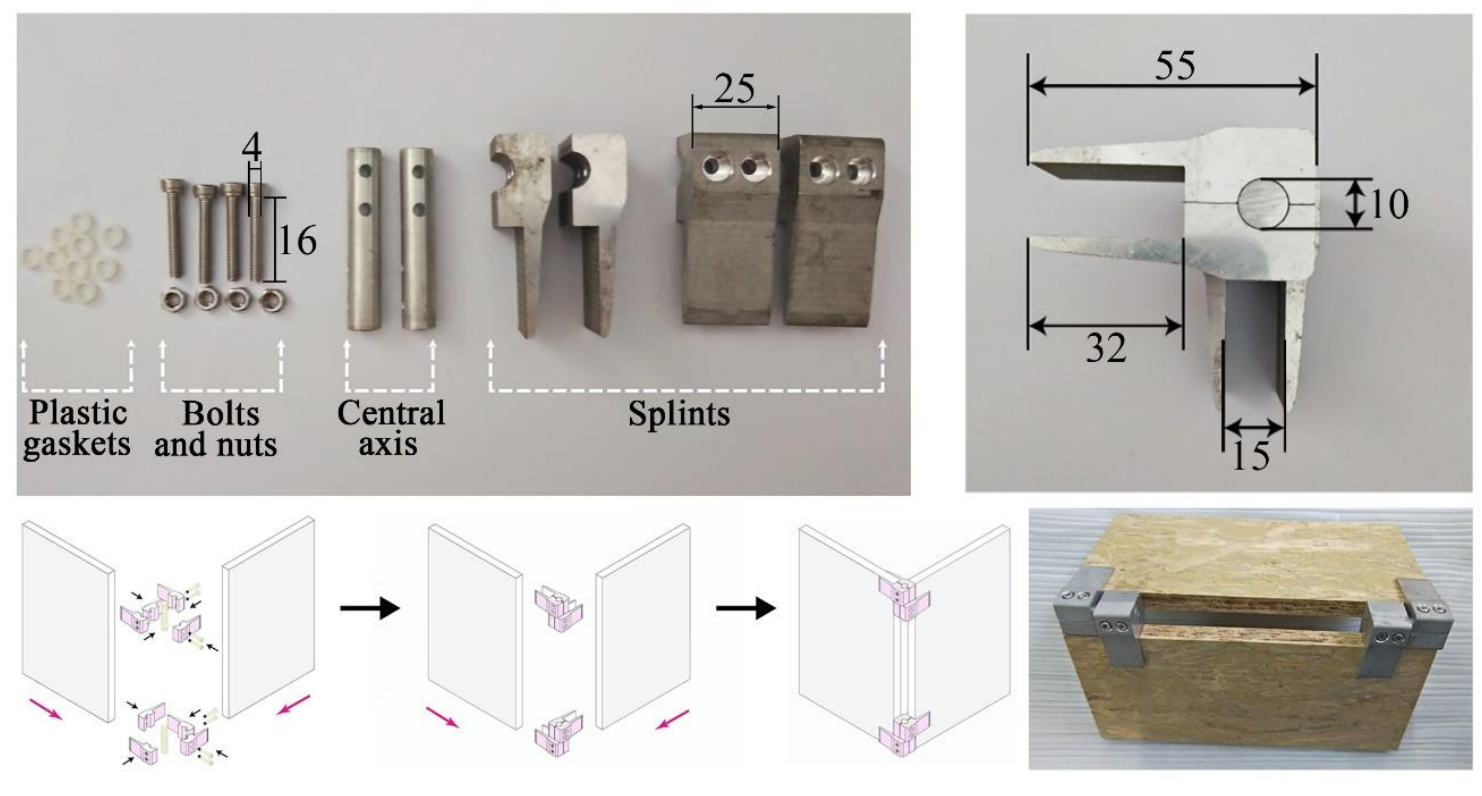

Fig. 2. Splint-type connector dimensions $(\mathrm{mm})$ and installation modes 


\section{Common connectors}

Six common connectors on the market were selected: a plastic buckle, three-in-one connector, transparent butterfly corner connector, two-in-one connector, wooden dowel pins, and a white corner connector. Figure 3 shows their dimensions.

(a)

(d)

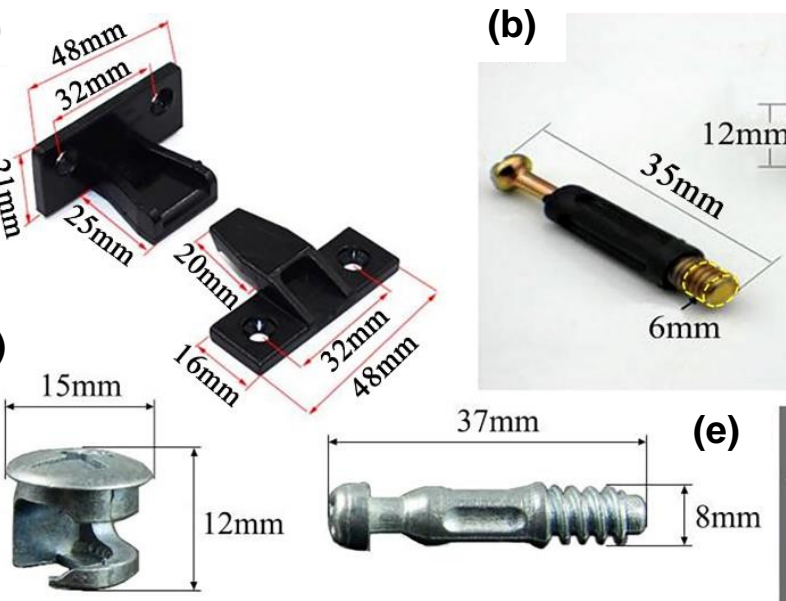

(b)

$15 \mathrm{~mm}$

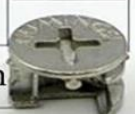

$10.5 \mathrm{~mm}$

$10.5 \mathrm{~mm}$

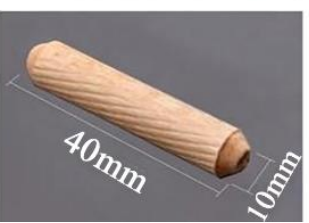

(c)

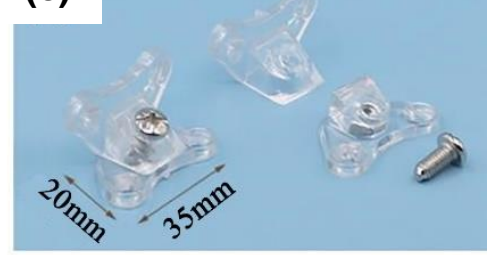

(f)

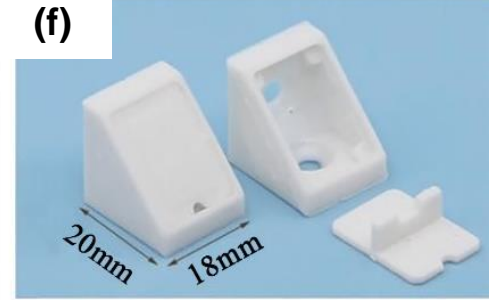

Fig. 3. Common L-type connectors: (a) plastic buckles; (b)three-in-one connectors; (c) transparent butterfly corner connectors; (d) two-in-one connectors; (e) wooden dowel pins; and (f) white corner connectors

\section{Material properties}

In this experiment, BOSB and WOSB were selected and provided by Yunnan Yonglifa Forestry Co., Ltd. (Dehong, China) and Beixin International Wood Industry Co., Ltd. (Beijing, China), respectively. Studies of elastic properties and moisture content of wood-based composites were carried out in accordance with standard requirements [EN-322 1993; EN-323 1993; ASTM D 1037 1993]. Table 1 lists the basic physical and mechanical indexes of BOSB and WOSB.

Table 1. Basic Physical and Mechanical Indexes of BOSB and WOSB

\begin{tabular}{|c|c|c|c|c|}
\hline Type & Density $\left(\mathrm{g} / \mathrm{cm}^{3}\right)$ & Water Content (\%) & $\begin{array}{c}\text { Elastic Modulus } \\
(\mathrm{MPa})\end{array}$ & $\begin{array}{c}\text { Static Bending } \\
\text { Strength (MPa) }\end{array}$ \\
\hline BOSB & 0.8 & 12.71 & 12811 & 107.56 \\
\hline WOSB & 0.55 & 7.2 & 1624.12 & 12.85 \\
\hline
\end{tabular}

Preparation of L-type test samples

Table 2 lists the size and quantity of the test samples.

Table 2. Size and Quantity of the Test Samples

\begin{tabular}{|c|c|c|c|c|}
\hline \multirow{2}{*}{ Connector Types } & \multicolumn{2}{|c|}{$\begin{array}{c}\text { L-type Cantilever Bending Test } \\
\text { Samples }\end{array}$} & $\begin{array}{c}\text { Corner Tension and Compression Test } \\
\text { Samples }\end{array}$ \\
\cline { 2 - 5 } & Size/mm & Quantity & Size/mm & Quantity \\
\hline $\begin{array}{c}\text { Six Common } \\
\text { Connectors }\end{array}$ & $150 \times 270 \times 15$ & 60 & $150 \times 270 \times 15$ & 120 \\
\hline Splint-type Connectors & $157.3 \times 270 \times 15$ & 10 & $127.3 \times 270 \times 15$ & 20 \\
\hline V-type Connectors & $156.5 \times 270 \times 15$ & 10 & $126.5 \times 270 \times 15$ & 20 \\
\hline $\begin{array}{l}\text { Note: Five groups of repeated samples were used in this experiment; BOSB and WOSB panels were } \\
\text { used in this experiment; and the same size and quantity of the test samples were utilized in the corner } \\
\text { tension and corner compression tests. }\end{array}$ \\
\hline
\end{tabular}

Xu et al. (2021). "Clamp connectors for bamboo OSB," BioResources 16(2), 2906-2920. 2909 
In relation to the different connectors, the drilling position of the test samples and installation position of the connectors were different. Figure 4 shows the installation hole position and size of the wooden dowel pins. The wooden dowel pins had to be coated with white latex in the hole during installation. The connectors were installed at room temperature, and had to be placed at room temperature for 1 week after installation.

A

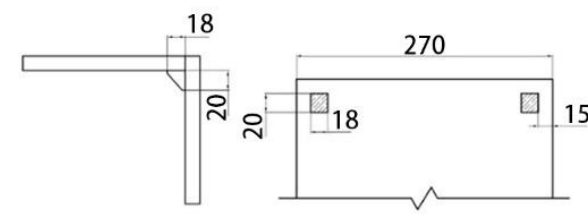

B

C
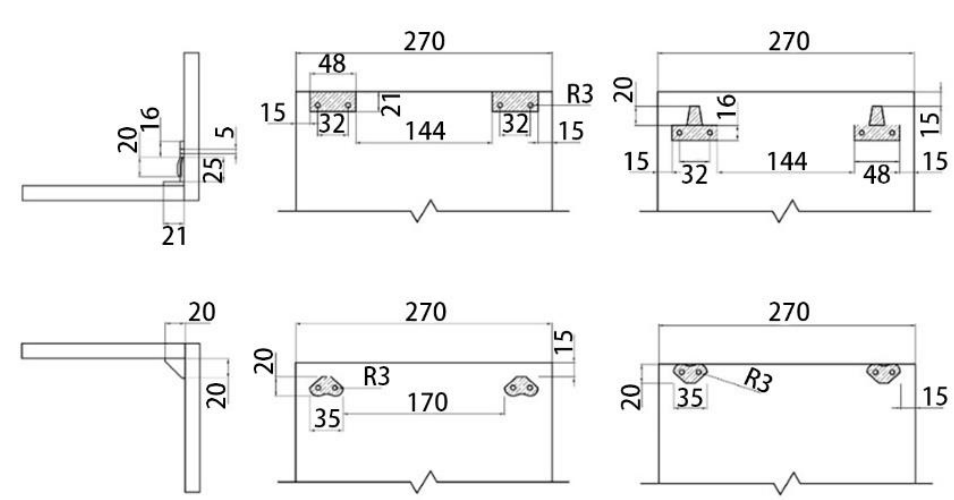

D

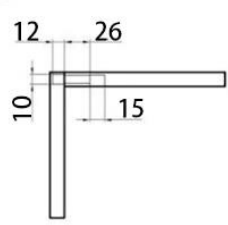

$\mathbf{E}$

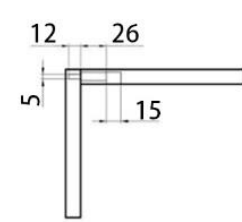

$\mathbf{F}$
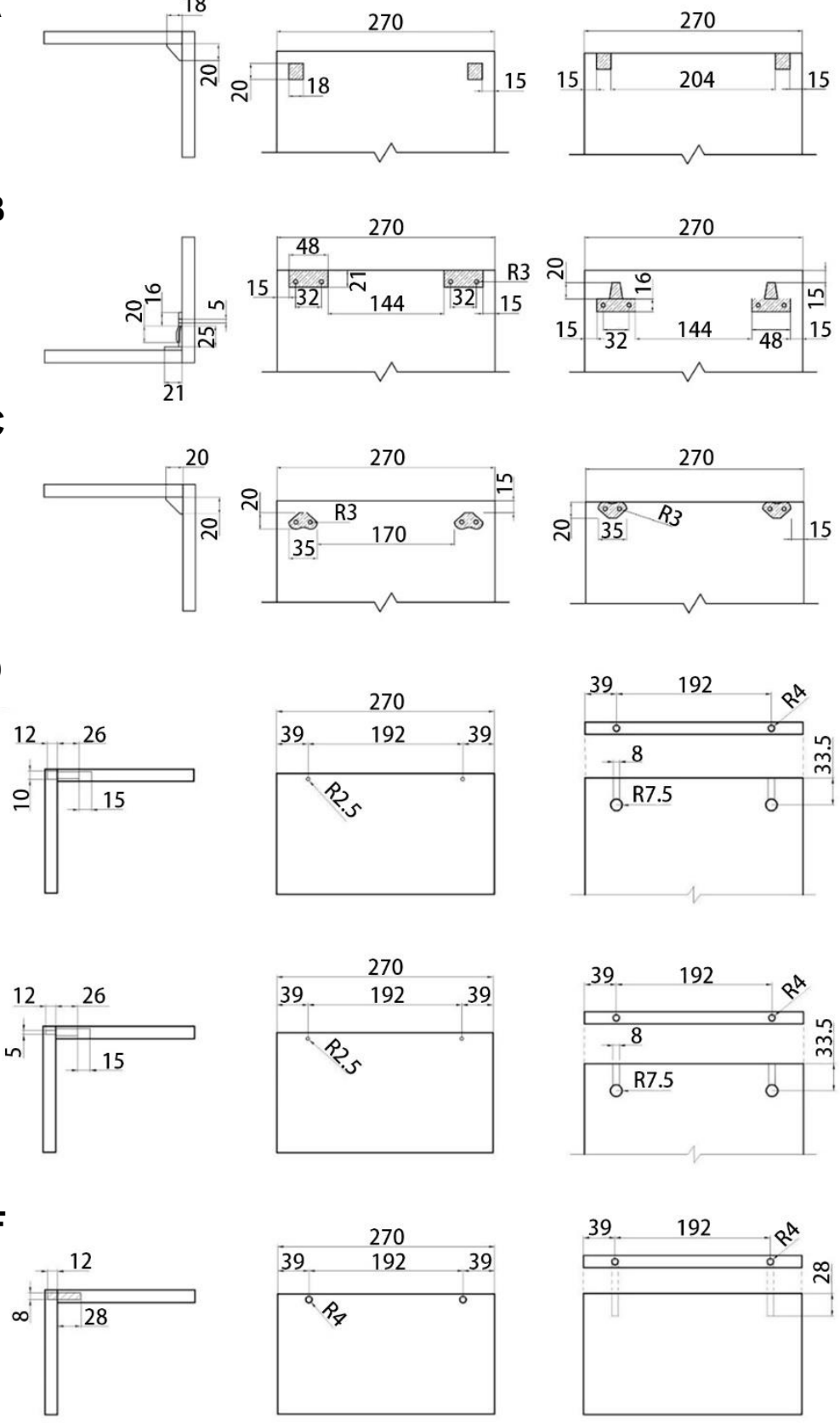

Fig. 4. Common connectors position and size (mm): A-white corner connectors; B-plastic buckles; Ctransparent butterfly corner connectors; D-three-in-one connectors; E-two-in-one connectors; and Fwooden dowel pins 


\section{Methods}

\section{Cantilever bending test}

The universal strength testing machine (Model WDW-100E, Jinan Chenda Testing Machine Manufacture Co., Ltd., Jinan, China) was employed to perform cantilever bending tests at a loading speed of $5 \mathrm{~mm} / \mathrm{min}$ to obtain the maximum load (Derikvand and Ebrahimi 2014; Yildirim et al. 2015) (Fig. 5). The load measurement accuracy was $0.01 \mathrm{~N}$, while the displacement measurement accuracy was $0.01 \mathrm{~mm}$, respectively. The room temperature and relative humidity were 25 to $30{ }^{\circ} \mathrm{C}$ and 35 to $45 \%$, respectively. The cantilever ultimate bending moment was calculated in Eq. 1,

$$
M=P_{\max } \times L
$$

where $M$ represents the ultimate bending moment $(\mathrm{N} \cdot \mathrm{m}), P_{\max }$ is the ultimate load $(\mathrm{N})$, and $L$ is the cantilever length $(\mathrm{m})$.

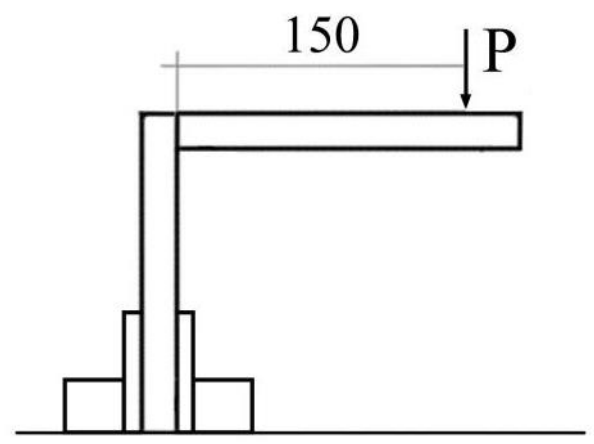

Fig. 5. Loading mode of the samples $(\mathrm{mm})$

\section{Corner tension and compression tests}

A mechanical testing machine (model: WDW-100E, Jinan Chenda Testing Machine Manufacture Co., Ltd., Jinan, China) was employed for loading at a speed of $5 \mathrm{~mm} / \mathrm{min}$ (Fig. 6).

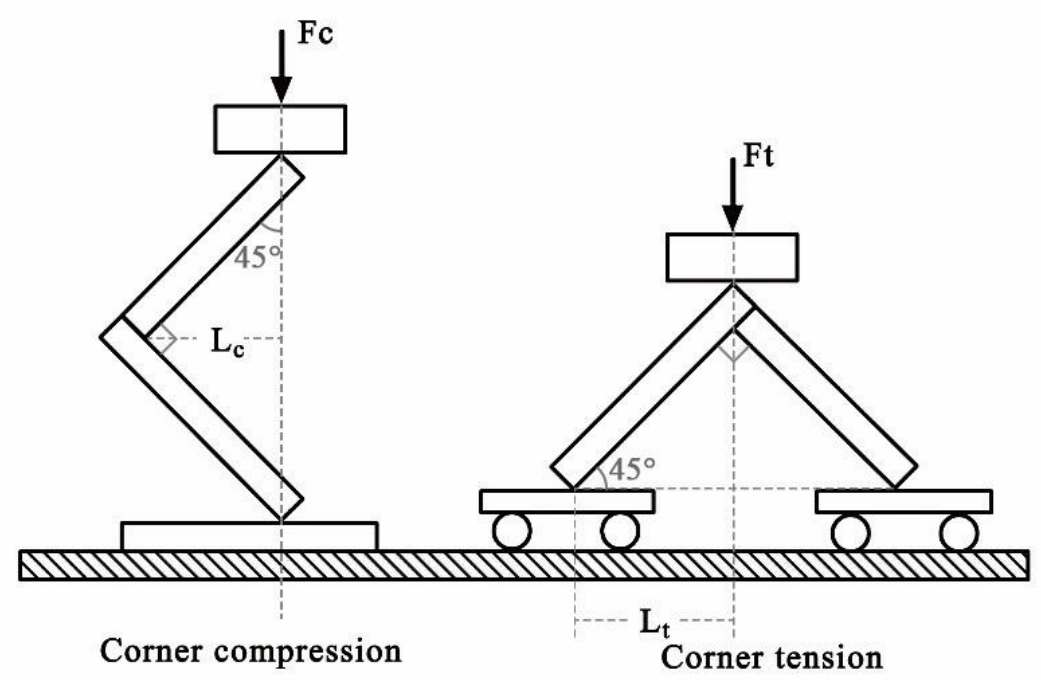

Fig. 6. Loading mode of the samples: (a) corner compression and (b) corner tension 
After the load reached the peak value, the machine continued to press down until the load decreased to $80 \%$ of the maximum load, and the test stopped (Šimek and Koňas 2012; Smardzewski et al. 2017; Podskarbi and Smardzewski 2019). The bending moment was calculated in Eqs. 2 and 3;

$$
\begin{aligned}
& M_{c}=F_{c} L_{c} \\
& M_{T}=0.5 F_{t} L_{t}
\end{aligned}
$$

where $M_{c}$ is the bending moment resistance of the joint under compression loading $(\mathrm{N} \cdot \mathrm{m}), M_{T}$ is the bending moment resistance of the joint under tension loading $(\mathrm{N} \cdot \mathrm{m}), P_{\max }$ is the maximum load in each test sample $(\mathrm{N}), L_{c}$ is the moment arm in compression $(\mathrm{m})$, and $L_{t}$ is moment arm in tension (m).

\section{RESULTS AND DISCUSSION}

\section{Bending Moment}

Cantilever bending

The variance analysis results in Table 3 confirmed an important difference between the cantilever ultimate bending moments of the eight connector types. Figure 7 shows the cantilever ultimate bending moments for the eight joints. Under a cantilever bending load, the ultimate bending moment of the joints fixed by the two new connectors was considerably greater than those with the other common connectors. The ultimate bending moment of the BOSB members fixed by the V-type connectors was $133 \mathrm{~N} \cdot \mathrm{m}$, which was greater than the BOSB members fixed by the splint-type connectors. However, the ultimate bending moment of the WOSB members fixed by the V-type connectors was less than those fixed by the splint-type connectors, indicating that the splint-type connectors were more suitable for fixing WOSB, while V-type connectors were more suitable for fixing BOSB. This result was possibly related to the larger friction and larger contact area between the splint-type connectors and WOSB. In addition, after the cantilever compressions, the joints fixed by the splint-type connectors failed due to connector deformations, and the joints fixed by the V-type connectors failed due to the panel breaking. Therefore, when V-type connectors were used for BOSB, the connection strength was greater than the splint-type connectors. This result also suggested that the strength of the V-type connectors was greater than the splint-type connectors.

Table 3. ANOVA Results of Cantilever Bending Moment of Joints

\begin{tabular}{|c|c|c|c|c|c|c|}
\hline Material & Variance Source & $\begin{array}{c}\text { Sum of } \\
\text { Squares }\end{array}$ & $\begin{array}{c}\text { Degrees of } \\
\text { Freedom }\end{array}$ & $\begin{array}{c}\text { Mean } \\
\text { Square }\end{array}$ & $\mathrm{F}$ & $\begin{array}{c}\text { Level of } \\
\text { Significance }\end{array}$ \\
\hline \multirow{3}{*}{ BOSB } & Between Groups & 53500.966 & 7 & 7642.995 & 1107.450 & 0.000 \\
\cline { 2 - 7 } & Within Groups & 200.142 & 29 & 6.901 & & \\
\cline { 2 - 7 } & Total & 53701.108 & 36 & & & 0.000 \\
\hline \multirow{3}{*}{ WOSB } & Between Groups & 9520.889 & 7 & 1360.127 & 114.235 & \\
\cline { 2 - 7 } & Within Groups & 357.191 & 30 & 11.906 & & \\
\cline { 2 - 7 } & Total & 9878.080 & 37 & & & \\
\hline
\end{tabular}

Among the six common connectors, the two-in-one connectors exhibited the highest cantilever ultimate bending moment, followed by the wooden dowel pins. The cantilever ultimate bending moments of the BOSB and WOSB members fixed by the two-in-one connectors were

Xu et al. (2021). "Clamp connectors for bamboo OSB," BioResources 16(2), 2906-2920. 2912 
36.3 N.m and 17.1 N.m, while those of the BOSB and WOSB members fixed by the V-type connectors were roughly 3.7 and 2.9 times the aforementioned values. Compared to the common connectors on the market, the two new connectors designed herein were more suitable for connecting BOSB and WOSB.

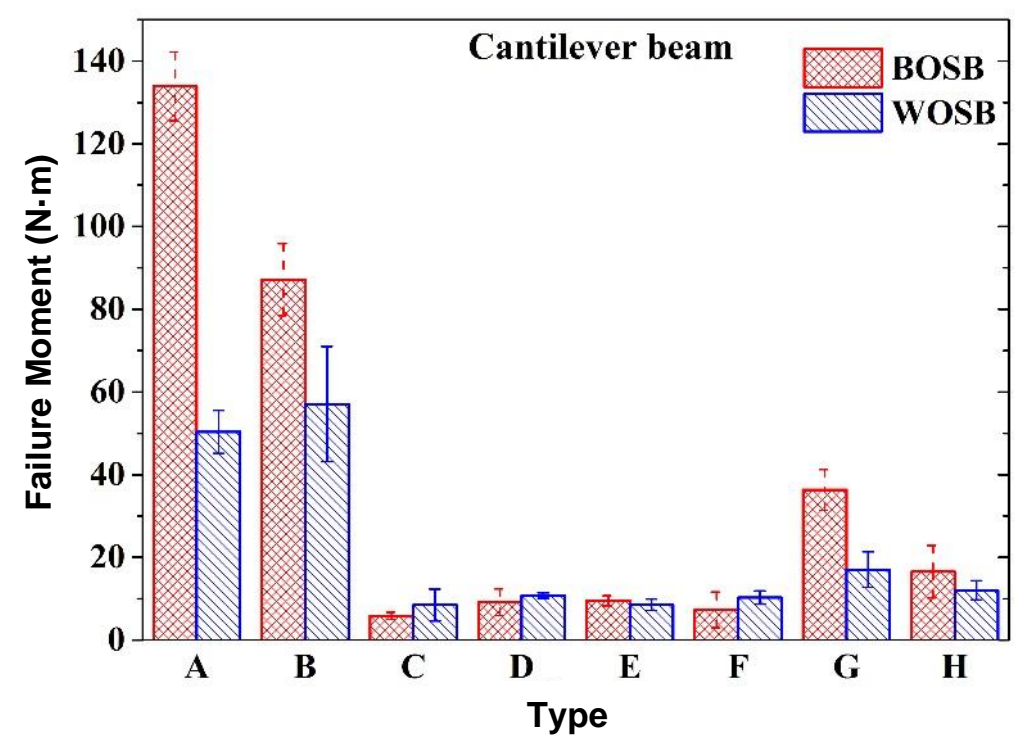

Fig. 7. Ultimate bending moment of L-type members under cantilever bending load: A-V-type connectors; B-splint-type connectors; C-plastic corner connectors; D-plastic buckles; E-butterfly corner connectors; Fthree-in-one connectors; G-two-in-one connectors; and H-wooden dowel pins

\section{Corner compression}

Figure 8 shows the ultimate bending moment for OSB members subjected to inward compression.

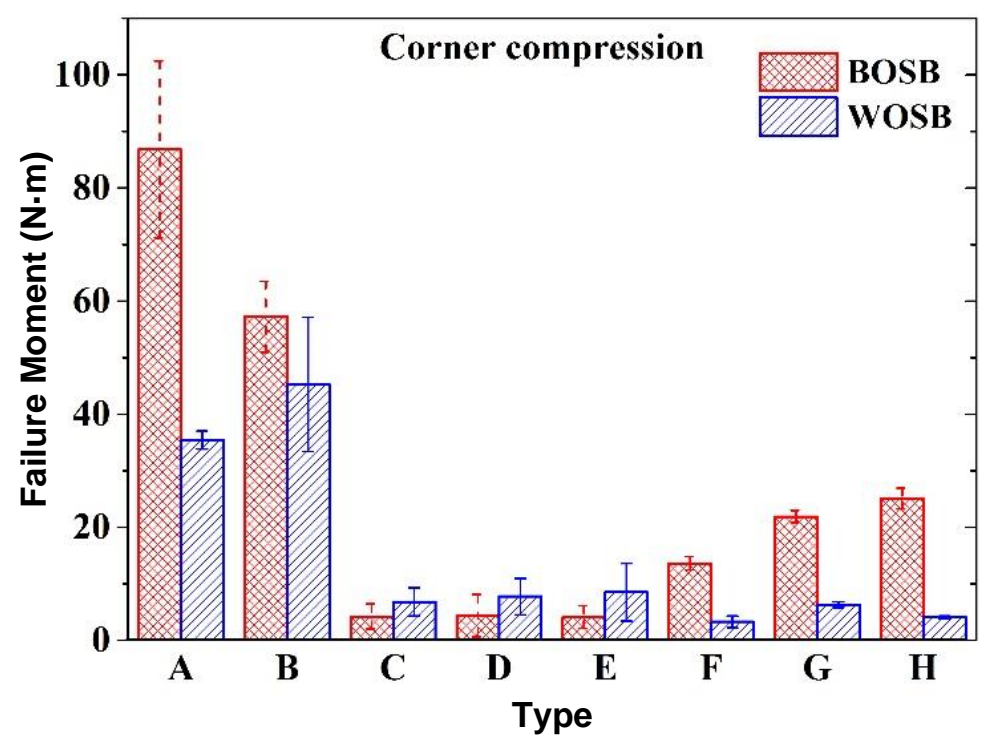

Fig. 8. Ultimate bending moments of L-type members under compression: A-V-type connectors; B-splinttype connectors; C-plastic corner connectors; D-plastic buckles; E-butterfly corner connectors; F-three-inone connectors; G-two-in-one connectors; and H-wooden dowel pins 
The comparison of Figs. 7 and 8 revealed that the inward compression moment of the member fixed by the new connectors was considerably less than the tension compression and cantilever compression. However, the change rule for the ultimate moment under inward compression was similar to that under cantilever bending. For example, the ultimate bending moments of the two new connectors were considerably greater than the common connectors, and the ultimate bending moment for the BOSB joints was greater than the WOSB joints. Moreover, the ultimate moments of the joints under inward compression for the BOSB members fixed by the two new connectors were greater than $57 \mathrm{~N} \cdot \mathrm{m}$. This value was 2.3 to 14 times that of BOSB members fixed by common connectors.

In addition, the ultimate moments of joints under inward compression for those fixed by the six common connectors exhibited a slight difference. Among them, the ultimate moments of joints under inward compression for the WOSB members fixed by the plastic corner connectors, plastic buckles, and butterfly corner connectors were greater than the BOSB members. The ultimate moments of joints under inward compression for the WOSB members fixed by three-inone connectors, two-in-one connectors, and wooden dowel pins were less than the BOSB members. Moreover, the variance analysis results also revealed notable differences between the ultimate moments of joints under inward compression for the different connectors (Table 4). This result suggested that different materials require different connectors and that the connector and connection strength between connectors and panels considerably affects the joint strength.

Table 4. ANOVA Results of Ultimate Moments of Joints under Inward Compression

\begin{tabular}{|c|c|c|c|c|c|c|}
\hline Material & Variance Source & $\begin{array}{c}\text { Sum of } \\
\text { Squares }\end{array}$ & df & Mean Square & $\mathrm{F}$ & $\begin{array}{c}\text { Level of } \\
\text { Significance }\end{array}$ \\
\hline \multirow{3}{*}{ BOSB } & Between Groups & 29042.112 & 7 & 4148.873 & 208.212 & 0.000 \\
\cline { 2 - 7 } & Within Groups & 557.934 & 28 & 19.926 & & \\
\cline { 2 - 7 } & Total & 29600.046 & 35 & & & \\
\hline \multirow{3}{*}{ WOSB } & Between Groups & 10400.643 & 7 & 1485.806 & 73.370 & 0.000 \\
\cline { 2 - 8 } & Within Groups & 546.774 & 27 & 20.251 & & \\
\cline { 2 - 7 } & Total & 10947.418 & 34 & & & \\
\hline
\end{tabular}

\section{Corner tension}

Figure 9 shows the ultimate bending moment under tension for the OSB members. The ultimate moments under tension for the BOSB and WOSB members fixed by the two new connectors (except for WOSB members fixed by V-type connectors) were greater than the six common connectors. Notable differences among the eight connector types were observed (Table 5). In addition, compared to the results of inward corner compression tests, the ultimate bending moment under tension load was higher.

For BOSB, the joints fixed by V-type connectors exhibited the best load-bearing capacity, and their tension ultimate bending moment was 2.7 to 5.8 times that of the other six common connectors. The second was the splint-type connector, where the tension ultimate moment was 1.8 to 4 times those of the six common connectors. Among the six common connectors, the connection performance decreased in the order of wooden dowel pins, transparent butterfly corner connectors, white corner connectors, plastic buckles, three-in-one connectors, and two-in-one connectors. Experimental results revealed that the V-type connectors and splint-type connectors designed herein were completely suitable for the existing OSB on the market, and their load-bearing capacities under tension and cantilever loading are meaningfully better than most other common connectors. Hence, the two new connectors could better guarantee the stability and safety of the joints.

Xu et al. (2021). "Clamp connectors for bamboo OSB," BioResources 16(2), 2906-2920. 2914 


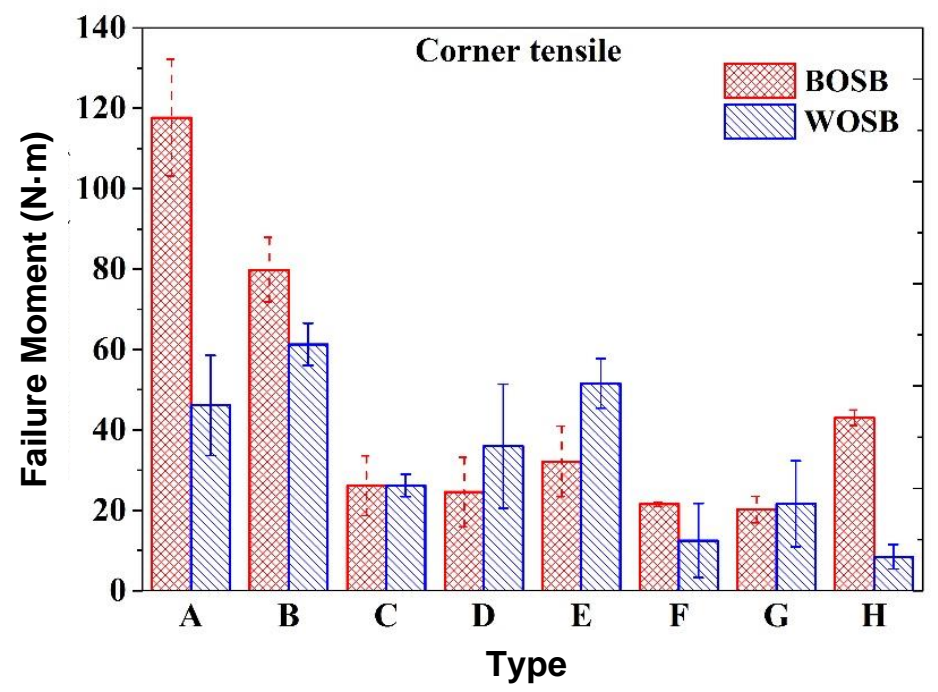

Fig. 9. Ultimate moments under tension load for L-type members: A-V-type connectors; B-splint-type connectors; C-plastic corner connectors; D-plastic buckles; E-butterfly corner connectors; F-three-in-one connectors; G-two-in-one connectors; and H-wooden dowel pins

Table 5. ANOVA Results of Tension Bending Moment of Joints

\begin{tabular}{|c|c|c|c|c|c|c|}
\hline Material & Variance Source & $\begin{array}{c}\text { Sum of } \\
\text { Squares }\end{array}$ & df & $\begin{array}{c}\text { Mean } \\
\text { Square }\end{array}$ & F & $\begin{array}{c}\text { Level of } \\
\text { Significance }\end{array}$ \\
\hline \multirow{3}{*}{ BOSB } & Between Groups & 21456.583 & 7 & 3065.226 & 325.771 & 0.000 \\
\cline { 2 - 7 } & Within Groups & 263.456 & 28 & 9.409 & & \\
\cline { 2 - 7 } & Total & 21720.040 & 35 & & & \\
\hline \multirow{3}{*}{ WOSB } & Between Groups & 6065.487 & 7 & 866.498 & 240.823 & 0.000 \\
\cline { 2 - 7 } & Within Groups & 97.148 & 27 & 3.598 & & \\
\cline { 2 - 7 } & Total & 6162.635 & 34 & & & \\
\hline
\end{tabular}

\section{Failure Modes}

Figures 10 through 12 show the fracture morphology photographs of furniture joints under cantilever bending load, inward compression, and outward tension. Generally, WOSB joint deformation was clearer than BOSB mainly because the mechanical strength of WOSB was less than BOSB, and the load it could bear was smaller. The panels of WOSB members fixed by the splint-type connectors exhibited clear cracks and delamination (Figs. 10a, 11a, and 12a). The panels of BOSB members fixed by the splint-type connector were slightly deformed, as well as the connector splints, and the panel surface where the connectors were fixed was damaged due to friction (Figs. 10b, 11b, and 12b). During the loading process, the failure of WOSB members fixed by the splint-type connectors was caused by the panel fracture, and the failure of BOSB members fixed by the splint-type connectors was caused by the connector deformation. However, the splinttype connector deformation in the BOSB joints was more serious than in the WOSB joints because the BOSB joints fixed by the splint-type connectors exhibited a higher ultimate bending moment. The splint-type connector deformation was more serious, which also indicated that the strength of the panel and connector, as well as their connection strength, affect the connection performance of furniture joints. Therefore, connectors with a similar panel strength should be selected for furniture use. 
(a)

(c)
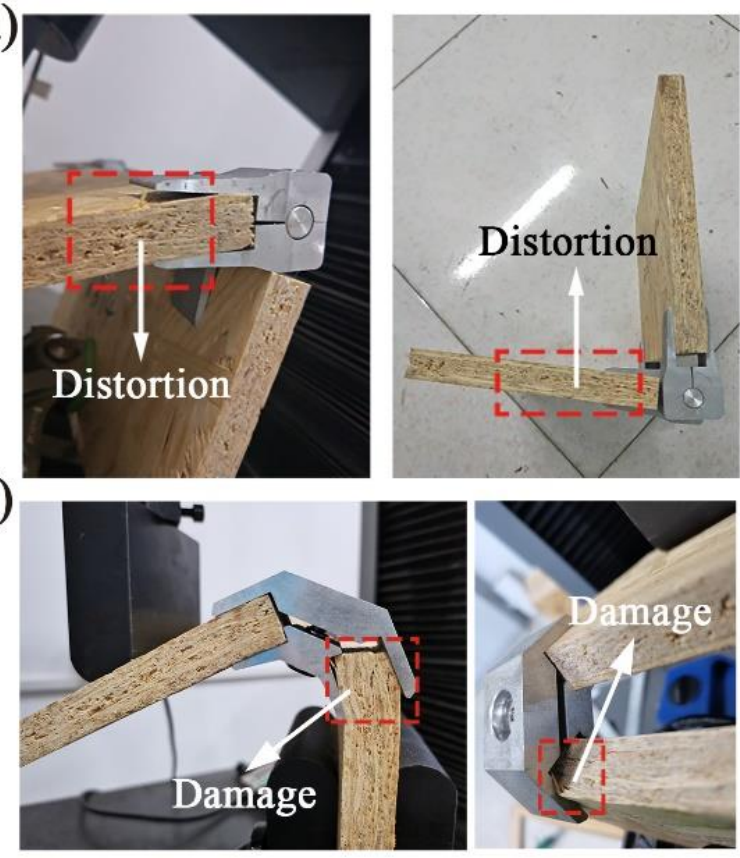

(b)

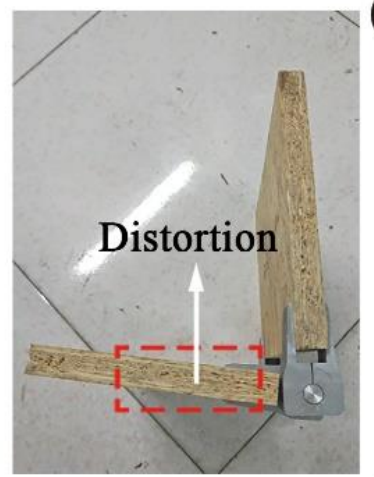

(d)
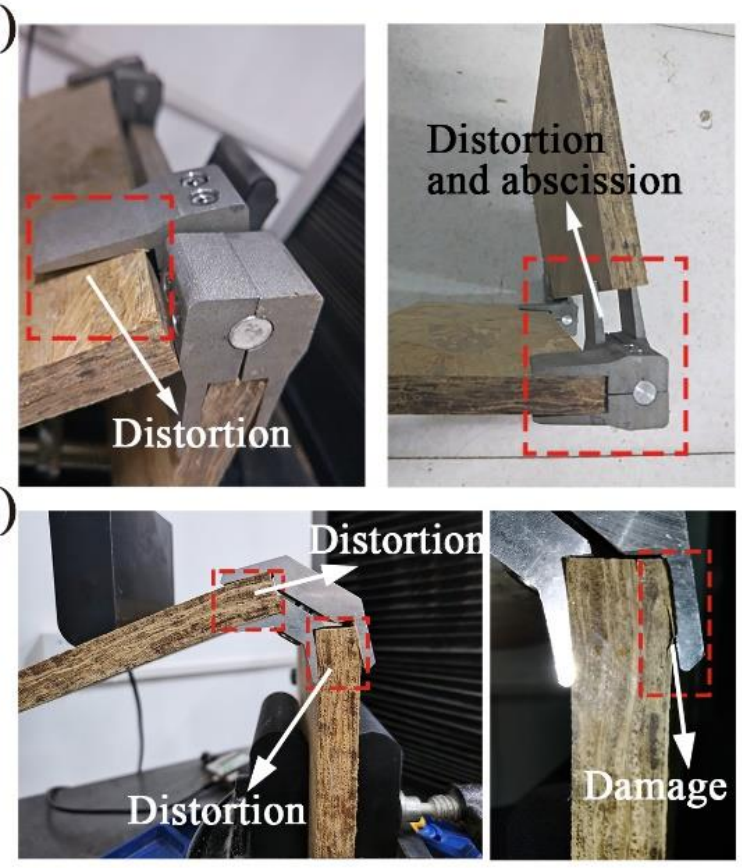

Fig. 10. Cantilever bending modes at failure for the joints fixed by new connectors : (a) WOSB members fixed by splint-type connectors; (b) BOSB members fixed by splint-type connectors; (c) WOSB members fixed by the V-type connectors; and (d) BOSB members fixed by the V-type connectors

(a)

(c)
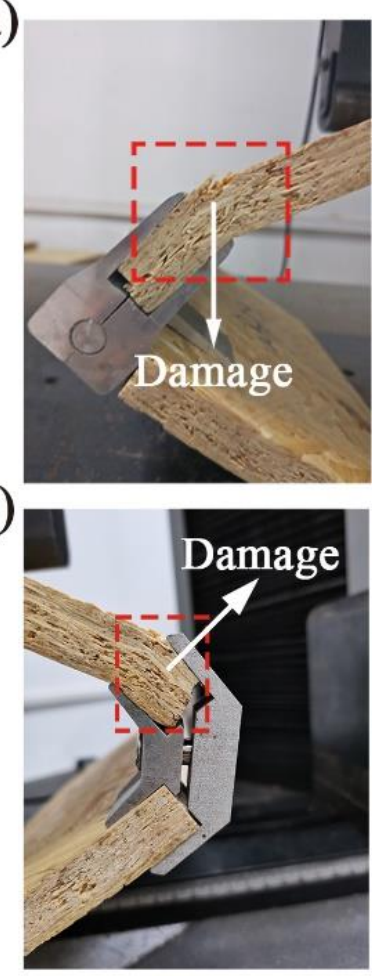
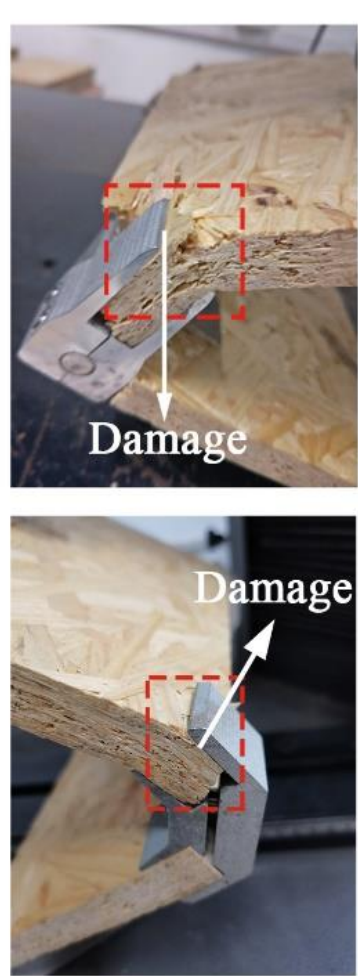

(b)

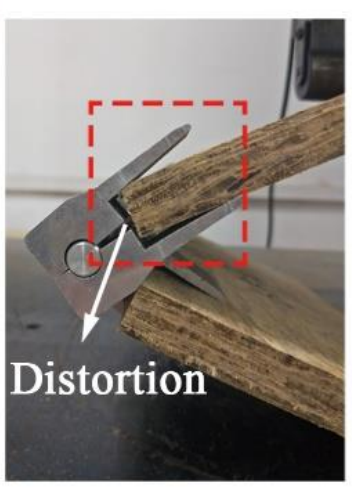

(d)

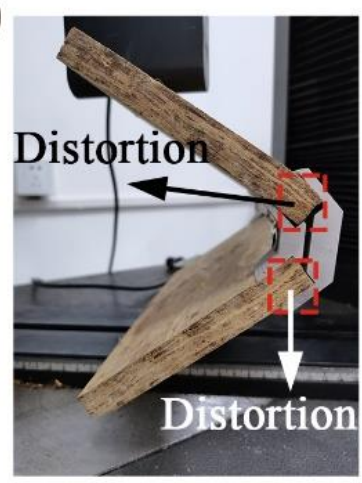

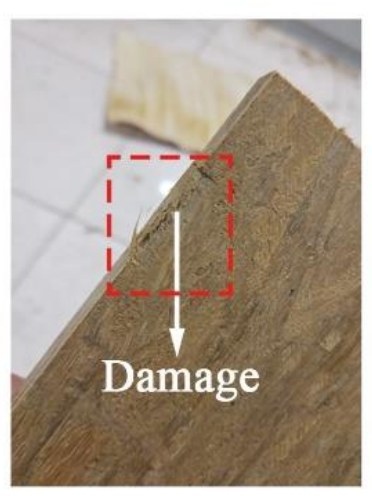

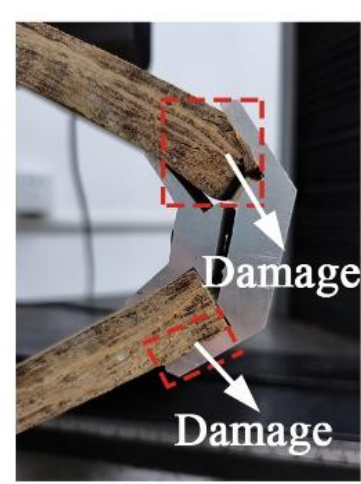

Fig. 11. Inward compression mode at failure for the joints fixed by new connectors: (a) WOSB members fixed by splint-type connectors; (b) BOSB members fixed by splint-type connectors; (c) WOSB members fixed by the V-type connectors; and (d) BOSB members fixed by the V-type connectors 

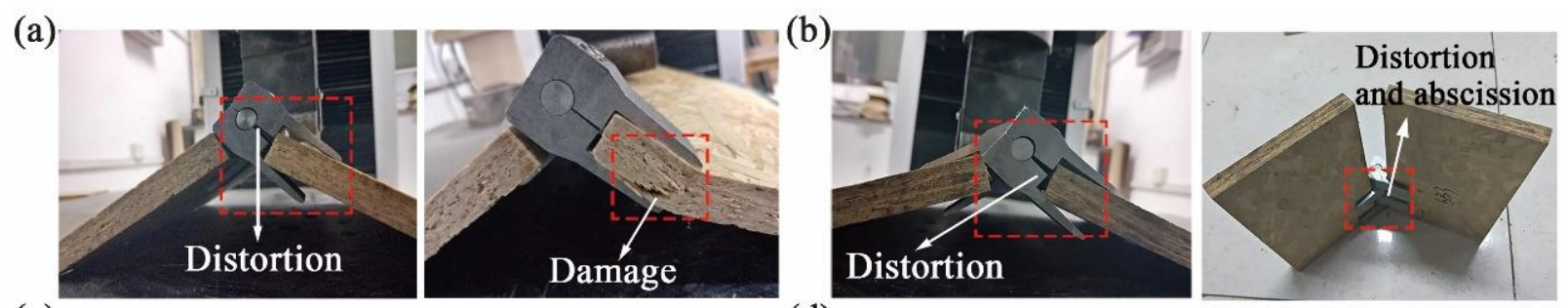

(c)
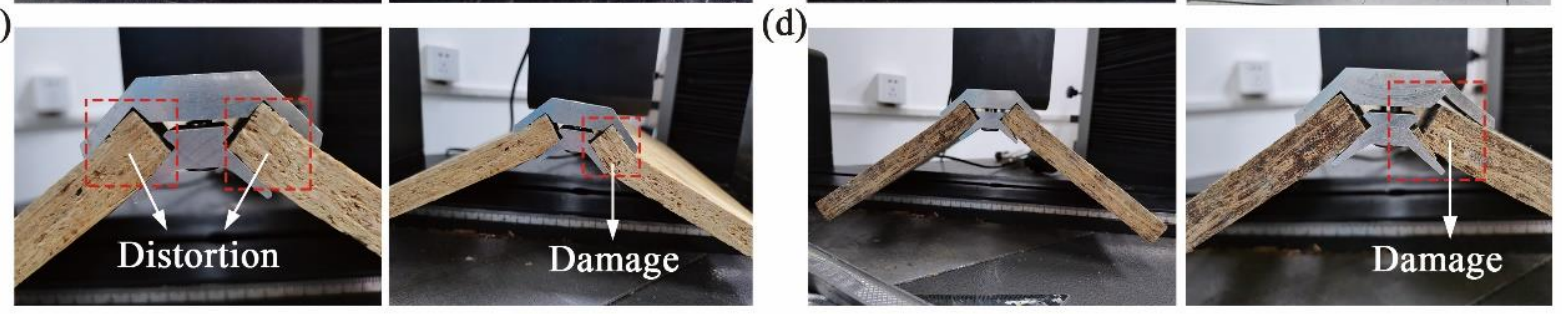

Fig. 12. Tension failure mode of the joints fixed by new connectors: (a) WOSB members fixed by splinttype connectors; (b) BOSB members fixed by splint-type connectors; (c) WOSB members fixed by the Vtype connectors; and (d) BOSB members fixed by the V-type connectors

Under the bending load, the panels of the WOSB members fixed by the V-type connectors were severely deformed, and the connection was broken and led to joint failure. In addition, the end of the BOSB members fixed by the same connector was deformed, and the bamboo shavings of the panel contact part fell off due to friction and led to panel cracks (Figs. 10d, 11d, and 12d). This phenomenon further illustrated the importance of the joint strength. The panel strength itself was extremely important because a stronger panel had less damage. As shown in the above figures, BOSB exhibited low deformation, but the connector exhibited large deformation, which resulted in the panel falling off. This result indicated the importance of compatibility between panels and connectors. High-strength panels should match high-strength connectors, while low-strength panels should match low-strength connectors. Thus, joint failure caused by the interaction of connectors and panels can be avoided.

The comparison of the damage in the two panel types revealed that when fixing BOSB, compared to the V-type connectors, the splint-type connectors were more prone to deformation and that the connection strength of the V-type connectors was better than the splint-type connectors. Therefore, V-type connectors were more suitable for BOSB. In addition, the connection strength of furniture joints was affected not only by the connection strength between the connectors and panels, but also by the strength of the connectors. Therefore, during furniture design, matching connectors should be selected according to different materials to obtain the best combination, to maximize the load-bearing capacity of the joints, and to ensure stability and safety.

\section{CONCLUSIONS}

1. The connection performance for fixing bamboo oriented strandboard (BOSB) and wood oriented strandboard (WOSB) for the two developed plug-in connectors was far better than the common connectors examined. Among the six common connectors, the connection performance of the two-in-one connectors and wooden dowel pins was better than the other connectors, and the bending moment of the BOSB members was greater than the WOSB members.

2. The connection performance comparison between the two new connectors revealed that the Vtype connectors were more suitable for BOSB. Their ultimate moment under cantilever

Xu et al. (2021). "Clamp connectors for bamboo OSB," BioResources 16(2), 2906-2920. 2917 
bending $(133.9 \mathrm{~N} \cdot \mathrm{m})$, inward compression $(86.8 \mathrm{~N} \cdot \mathrm{m})$, and outward tension $(117.7 \mathrm{~N} \cdot \mathrm{m})$ were greater than those of the splint-type connector, and the values were approximately 3.7 times those of the two-in-one connectors. The splint-type connector was more suitable for WOSB, and its ultimate bending moment $(57.1 \mathrm{~N} \cdot \mathrm{m}, 45.3 \mathrm{~N} \cdot \mathrm{m}, 61.3 \mathrm{~N} \cdot \mathrm{m})$ was considerably greater than the V-type connectors $(50.1 \mathrm{~N} \cdot \mathrm{m}, 35.4 \mathrm{~N} \cdot \mathrm{m}, 46.1 \mathrm{~N} \cdot \mathrm{m}$, respectfully).

3. Simple bending failure modes of BOSB and WOSB joints fixed by the two new connectors were observed. Failure of the WOSB joints was mostly caused by panel failure, while failure of the BOSB joints was caused by connector deformation, panel bending deformation, and separation of surface shavings. Moreover, the deformation resistance of V-type connectors was greater than the splint-type connectors.

4. The connection strength of the furniture joints was affected not only by panel strength, but also by the connector type and its own strength. For manufacturing furniture, suitable connectors should be selected according to material properties to improve furniture stability.

\section{ACKNOWLEDGMENTS}

The authors would like to express their heartfelt gratitude to the National Science and Technology Major Project of China (2016 YFD 0600905), China Natural Science Foundation (3180047). The authors would like to thank the anonymous reviewers and editor for their valuable comments and suggestions for improving the quality of this paper.

\section{REFERENCES CITED}

Akinlabi, E. T., Anane-Fenin, K., and Akwada, D. R. (2017). "Bamboo taxonomy and distribution across the globe," in: Bamboo: The Multipurpose Plant, E. Akinlabi, K. AnaneFenin, and D. R. Akwada (eds.), Springer International Publishing, Switzerland, pp. 1-37. DOI: $10.1007 / 978-3-319-56808-9 \_1$

Apriani, M. T. (2012). "Physical and mechanical properties of bamboo oriented strand board made from steamed pretreated bamboo strands under various bamboo species and resin content," IPB University.

ASTM D 1037 (1993). "Standard test methods for evaluating properties of wood-base fiber and particle panel materials," ASTM.

Bahari, S. A., Grigsby, W. J., and Krause, A. (2017). "Thermal stability of processed PVC/bamboo blends: Effect of compounding procedures," European Journal of Wood and Wood Products 75(2), 147-159. DOI: 10.1007/s00107-016-1148-5

Biswas, D., Bose, S. K., and Hossain, M. M. (2011). "Physical and mechanical properties of urea formaldehyde-bonded particleboard made from bamboo waste," International Journal of Adhesion and Adhesives 31(2), 84-87. DOI: 10.1016/j.ijadhadh.2010.11.006

Chaowana, P. (2013). "Bamboo: An alternative raw material for wood and wood-based composites," Journal of Materials Science Research 2(2), 90. DOI: 10.5539/jmsr.v2n2p90

Chen, S., Du, C., and Wellwood, R. (2010). "Effect of panel density on major properties of oriented strandboard," Wood and Fiber Science 42(2), 177-184.

Dalvand, M., Ebrahimi, G., Haftkhani, A. R., and Maleki, S. (2013). “Analysis of factors affecting diagonal tension and compression capacity of corner joints in furniture frames 
fabricated with dovetail key," Journal of Forestry Research 24(1), 155-168. DOI: 10.1007/s11676-013-0336-y

Derikvand, M. and Ebrahimi, G. (2014). "Finite element analysis of stress and strain distributions in mortise and loose tenon furniture joints," Journal of Forestry Research 25(3), 677-681. DOI: $10.1007 / \mathrm{s} 11676-014-0507-5$

EN-322 (1993). "Wood-based panels. Determination of moisture content," ISO International Standard.

EN-323 (1993). "Wood-based panels. Determination of density," ISO International Standard.

Febrianto, F., Jang, J. H., Lee, S. H., Santosa, I. A., and Kim, N. H. (2015). "Effect of bamboo species and resin content on properties of oriented Strand board prepared from steam-treated bamboo strands," BioResources 10(2), 2642-2655. DOI: 10.15376/biores.10.2.2642-2655

Febrianto, F., Sahroni, Hidayat, W., Bakar, E. S., Kwon, G. J., Kwon, J. H., Hong, S. I., and Kim, N. H. (2012). "Properties of oriented strand board made from Betung bamboo (Dendrocalamus asper (Schultes.f) Backer ex Heyne)," Wood Science and Technology 46(13), 53-62. DOI: 10.1007/s00226-010-0385-8

$\mathrm{Fu}$, Y., Fang, H., and Dai, F. (2017). "Study on the properties of the recombinant bamboo by finite element method," Composites Part B: Engineering 115, 151-159. DOI: 10.1016/j.compositesb.2016.10.022

Guo, Y., Qin, W., Chen, Y., Liu, S., and Zhu, Z. (2019). "Moment capacity of furniture corner joints made from bamboo-oriented strand board," Wood and Fiber Science 51(3), 255-263. DOI: $10.22382 /$ wfs-2019-024

Li, Q. (2001). "Prospect for re-combined bamboo timber," Journal of Bamboo Research

Qiang, X. (2008). "The study on joint property of oval-tenon of the glued laminated bamboo," Naijing Forestry Univesity.

Ratnasingam, J., and Ioras, F. (2013). "Effect of adhesive type and glue-line thickness on the fatigue strength of mortise and tenon furniture joints," European Journal of Wood and Wood Products 71(6), 819-821. DOI: 10.1007/s00107-013-0724-1

Sadegh, M., Akbar, R. H., Mosayeb, D., Mehdi, F., and Mehdi, T. (2012). "Bending moment resistance of corner joints constructed with spline under diagonal tension and compression," Journal of Forestry Research 23(3), 481-490. DOI: 10.1007/s11676-012-0288-7

Seitz, R. K., Seitz, G. A., Kobes, M. P., and Fister, L. H. (2003). "Furniture connection system and method," U. S. Patent No. US6543845B2

Šimek, M., and Koňas, P. (2012). "Bending stress modeling of dismountable furniture joints applied with a use of finite element method," Acta Universitatis Agriculturae Et Silviculturae Mendelianae Brunensis 57(1), 137-146. DOI: 10.11118/actaun200957010137

Smardzewski, J., Slonina, M., and Maslej, M. (2017). "Stiffness and failure behaviour of wood based honeycomb sandwich corner joints in different climates," Composite Structures 168(May), 153-163. DOI: 10.1016/j.compstruct.2017.02.047

Sumardi, I. and Suzuki, S. (2013). "Parameters of strand alignment distribution analysis and bamboo strandboard properties," BioResources 8(3), 4459-4467. DOI: 10.15376/biores.8.3.4459-4467

Podskarbi, M., and Smardzewski, J. (2019). "Numerical modelling of new demountable fasteners for frame furniture,” Engineering Structures 185(Apr. 15), 221-229. DOI:

10.1016/j.engstruct.2019.01.135

Vassiliou, V. and Barboutis, I. (2005). "Screw withdrawal capacity used in the eccentric joints of cabinet furniture connectors in particleboard and MDF," Journal of Wood Science 51(6), 572576. DOI: $10.1007 / \mathrm{s} 10086-005-0708-9$

Wan-Si, F. U. and Huang, J. (2007). “A study on manufacturing technology for bamboo OSB 
with PF resin," China Wood Industry 21(2), 7-9. DOI: 10.19455/j.mcgy.2007.02.003

Yildirim, M. N., Uysal, B., Ozcifci, A., Yorur, H., and Ozcan, S. (2015). "finite element analysis (fatigue) of wooden furniture strength," in: XXVII Furniture Research, Ankara, Turkey.

Yong, G., Zhu, S., and Chen, Y. (2018). "Contrastive analysis of screw withdrawal resistance between bamboo oriented strandboard and conventional particleboard," Wood Research. 63(6), 1071-1080.

Zhang, H. and Du. (2007). "Research and development of production technology of bamboo waferboard and oriented strand board based on biological characteristics and timber adaptability," Journal of Bamboo Research 26(2), 43-48.

Article submitted: December 6, 2020; Peer review completed: February 7, 2021; Revised version received and accepted: February 25, 2021; Published: March 2, 2021.

DOI: 10.15376/biores.16.2.2906-2920 